\title{
Article
}

\section{How do girls' magazines talk about breasts?}

\author{
Nicola Brown ${ }^{1}$, Christine Campbell ${ }^{1}$, Craig Owen ${ }^{2}$ and Atefeh Omrani ${ }^{1}$ \\ ${ }^{1}$ St Mary's University, Twickenham, UK. \\ ${ }^{2}$ Anglia Ruskin University, Cambridge, UK
}

\begin{abstract}
Girls' magazines play an important role in female adolescents' identity and their constructions of femininity. Despite breast development being common to all female adolescents, and breasts being a key signifier of femininity, the representation of breasts in girls' magazines has not been investigated. A Foucauldian discourse analysis was conducted to understand the ways in which breasts are represented in two popular girls' magazines (Teen Vogue and Seventeen). Articles in Seventeen promoted a contradictory and potentially confusing postfeminist discourse, supporting calls for Body Positivity, whilst at the same time framing breasts as problematic and encouraging girls to aspire to an ideal breast. The reader was positioned as a consumer with the purchase and wearing of bras offered as a neoliberal solution to these problems. In contrast, Teen Vogue articles conveyed a feminist informed Body Positivity discourse. Readers were positioned as active feminist advocates, incited to adopt radical, collective, political responses in order to challenge the potentially damaging messages surrounding breast ideals and sexualisation. We argue that consistent feminist messages are needed across and within media to support teenage girls in negotiating their bodies and identities.
\end{abstract}


Key Words adolescence; body positivity, breasts, discourse analysis, feminism, magazines, postfeminism

\section{Corresponding author}

Nicola Brown, Faculty of Sport, Health \& Applied Science, St Mary’s University, Waldegrave Rd, Twickenham, TW1 4SX, UK

Email: nicola.brown@stmarys.ac.uk

Female adolescence is a critical stage of identity development in which preoccupation with self-image is heightened (Firminger, 2006; Slater, Tiggemann, Hawkins \& Werchon, 2011) and feelings of vulnerability about fitting in intensify (Chittenden, 2010). This period of development coincides with physical changes that take place during puberty that are known to negatively influence body satisfaction and self-esteem (Robins \& Trzesniwski, 2005; Slater \& Tiggemann, 2010). Breast development is the first manifestation of puberty in approximately 85 percent of girls (Brooks-Gunn, Newman, Holderness \& Warren, 1994).

There is substantial variation in the dimensions of female breasts (Gefen \& Dilmoney, 2007), including variation in shape, symmetry, projection, and position on the chest wall (Avsar, Avgit, Belier, Top \& Taskinalp, 2010; Manning, Scutt, Whitehouse \& Leinster, 1997). However, breast size is the most publicly visible breast dimension (Lynn, 2009) and plays an important role in body image (Grogan, Brownbridge, Kilgariff, \& Whalley, 2012; Reaby, Hort \& Vandervord, 1994). In a survey of over 2000 female British adolescents aged 11 to 18 years, 87 percent reported at least one breast concern, with over a third reporting concerns about breast size (Brown, Smith, Brasher, Risius, Marczyk, 2017). These findings are 
concerning, yet unsurprising, if we consider how breast size is one of the main ways in which women's breasts are objectified in popular culture (Seifert, 2005; Swami \& Tovee, 2015; Tantleff-Dunn, 2001). Moreover, it has been argued that the media over-emphasises the sexual nature of breasts (Ward, Merriwether \& Caruthers, 2006) and does not reflect the normal variations of women's breasts (Smith, 2014).

The public nature of breast growth, and the social comparisons associated with this, are of great psychological significance. Indeed, as females develop breasts they are faced with the challenge of negotiating their own physical maturity, at a time when they are especially sensitive to what others think and how they look compared to their peers (McGrath \& Mukerji, 2000). This can alter their self-perceptions resulting in body dissatisfaction (Davies \& Furnham, 1986) and decreased self-esteem (Croll, 2005; Robins \& Trzesniewski, 2005). Breast growth can also increase females' self-consciousness as their developing bodies become the object of male sexual interest (Millsteed \& Firth, 2003), with this sexual objectification being reinforced in popular media, leading to an increase in young women's anxiety about how they are perceived by others (Frost, 2011).

\section{Representations of femininity and female bodies in girls' magazines}

Girls' magazines are a favoured form of mass media, offering beauty, fashion and entertainment content. These magazines provide advice, information and guidance to teens during their adolescence (Finders, 1996). This medium can play a role in teenagers' identities and constructions of femininity as they enter adulthood (Chow, 2004; Chittenden, 2010; Kaplan \& Cole, 2003; Keller, 2011). Brookes and Kelly (2009) report that these types of magazines give information on how to perform femininity, often through a "sisterly 
relationship" of trust, advice and understanding between the reader and the magazine (Pattee, 2004, p. 5).

The number of girls' magazines surged in number in the late 1990's (Davalos, Davalos \& Layton, 2007; Keller, 2011) and have long been a key source of feminist interest and critique (McRobbie, 2000), with researchers identifying a "murky brew of feminism, anti-feminism and postfeminism" infiltrating both material and digital publications (Jackson, 2018, p.33). Critical feminist researchers have highlighted how girls' magazines can perpetuate patriarchal notions of beauty and sexuality; that physical attractiveness is one of women's most important assets, and something all women should strive to achieve and maintain (Beale, Malson \& Tischner, 2016; Keller, 2011). Exposure to such messages and media representations of the female form can contribute to psychological distress, body image concerns and low self-esteem (Dohnt \& Tiggemann, 2006; Grabe, Ward \& Hyde, 2008; Hawkins, Richards, MacGranley \& Stein, 2004; Jones, Vigfusdottir \& Le, 2004), and thus is an important public health issue.

Paradoxically, some feminist scholars argue that girls' magazines offer a platform for female empowerment and the popularisation of feminism; offering spaces for social acceptance and circulating images of alternative forms of girlhood (Karlyn, 2009; Keller, 2015). This empowerment argument has been supported by the emergence of the Body Positivity movement which broadly claims to challenge stigma towards bodies which are not deemed beautiful by traditional standards (Sastre, 2014). But this movement has been critiqued by some commentators (e.g. Gill \& Elias, 2014) as not representing a straightforward liberation from beauty standards, rather adding an extra requirement to have a "beautiful mind" (p.183). Moreover, a tension between these ostensibly anti-feminist and feminist discourses can be 
found even within the same title. For example, following a textual analysis of over 200 articles featuring body related content in Seventeen magazine, Ballentine and Ogle (2005) identified that half the content portrayed unrealistic ideals, in contrast the other half encouraged readers to ignore prevalent discourses to have a perfect body and instead focus on health rather than appearance.

Feminist researchers have also identified how magazines aimed at girls and young women can be a vehicle for postfeminist messages. For McRobbie (2009), a key characteristic of postfeminism is the contradictory nature or 'double entanglement' of discourse about feminism, wherein it is taken as common sense, whilst at the same time refuted. In turn, Gill (2007, 2016) conceptualises postfeminism as a sensibility that consists of an interrelated, yet contradictory, group of features including: the pervasive sexualisation of contemporary culture; a shift from viewing women as sexual objects to sexual subjects; the increasing surveillance of women's bodies; the promotion of a self-improvement culture endorsed by the beauty industry; the silencing of discourse about structural, cultural and economic inequalities; and the championing of the neoliberal rationalities of individualism, choice, and consumption.

As an example, Jackson (2005) and Jackson and Westrupp (2010), argue that girls' magazines have become a purveyor of postfeminist sexuality, packaged with content about sexual techniques (e.g. how to kiss and 'snog' boys) and safe sex. In their analysis of Australasian girls' magazines they demonstrate how postfeminist ambivalences permeate the magazine content, with juxtaposing articles calling upon competing discourses of desire and danger. The former promoting messages that girls can be sexually free, sophisticated, 
empowered, and 'savvy', and the latter requiring girls to not be too assertive, and to engage in (hetero)sexual self-surveillance and be responsible in their sexual interactions with boys.

The multiple, often contradictory representations of femininity and the female form in girls' magazines have received considerable attention from feminist scholars. However, despite breast development being common to all female adolescents and a key signifier of femininity, the representation of breasts in girls' magazines has been overlooked. This study aimed to further advance research in this field by critically examining the discourses in two popular girls' magazines, Seventeen and Teen Vogue. This led to two research questions: 1) What discourses are deployed in articles on breasts in these two magazines? 2) What are the implications of these discourses in terms of the subject positions made available to the readers and writers?

\section{Materials and methods}

\section{Materials}

Reflecting the move in the magazine industry towards online publications (Rowlands, 2013), we analysed the representation of breasts in online editions of Seventeen and Teen Vogue, two magazines which are aimed at similar demographics. These are the market leading titles in the United States, which have world-wide penetration thanks to their online provision.

Seventeen. First launched in 1944, Seventeen is now the largest selling teen beauty and fashion magazine, reaching nearly 5 million young women, aged 12 to 24 years (Hearst, 2019). Although the magazine caters to teenage girls, Seventeen reports that the median age of its readers is 23.9 years (Heart, 2019). At the start of 2017 the magazine reduced its hard 
copy publication frequency from 10 issues a year to six, to focus on online content. The magazine's online website (Seventeen.com) receives 2.7 million visitors per month (Hearst, 2019), with the majority of traffic from the US (36.8\%), followed by the UK (8.0\%) and Canada (6.3\%) (SimilarWeb, 2019). Seventeen reports on a variety of topics including fashion, beauty, entertainment, love, life and health.

Teen Vogue. Launched in February 2003, Teen Vogue is a fashion and entertainment magazine for girls. Teen Vogue has over one million subscribers and delivers a variety of content through a combination of print, TeenVogue.com, 15 social media platforms, and a video channel (CondeNast, 2017). Following a steep decline in teen fashion magazine sales in recent years, Teen Vogue cutback on its print distribution in 2015 in favour of online content. The number of US website visitors more than doubled from 2.9 million in January 2016 to 7.9 million in January 2017 (Fernandez, 2017). In June 2019 it was reported that the majority of visitors to teenvogue.com come from the US (44.6\%), with the UK (8.3\%) and Canada (5.3\%) the second and third highest (SimilarWeb, 2019). In addition to news and politics, the articles typically focus on fashion, entertainment, beauty, lifestyle, and wellness.

\section{Search strategy}

To identify relevant articles, the authors used the search engines provided on the magazine websites and used the search terms 'breasts', 'boobs', and 'bras'. No date restriction was imposed on the search. All articles published online where breasts or bras were the primary focus were included. In total, the data corpus consisted of 105 articles; 51 from Teen Vogue (published from 03/2015 to 11/2017) and 54 from Seventeen (published from 01/2015 to 11/2017). 


\section{Analytic approach}

We followed Willig's (2013) six steps of Foucauldian discourse analysis to identify how the articles collectively produced particular ways of speaking about and representing breasts. We paid particular attention to the ways in which social, cultural and historical contexts informed understandings of what are deemed 'natural', 'normal' and 'ideal' shapes, sizes, functions and meanings of breasts.

Initially, the second and third authors divided the data corpus between them and through reading, re-reading and coding the data, identified the main 'objects of discourse': the common ways in which breasts, bras and related issues were discussed. This process included the exchange and re-coding of a sub-set of articles to check the reliability of the initial codes. Step two was to share their initial analyses with the other members of the research team and identify the competing, and potentially contradictory, ways in which breasts were represented. The third step was to discuss the potential consequences of these representations, in terms of femininity, feminism, consumption, body-positivity and the sexualisation of women's bodies. Next, we explored how these different representations made particular subject positions available for the writer and reader. The final two steps involved looking at practice and subjectivity. This involved analysing the roles, characters and types of person the reader was able to inhabit or connect with in the text, and what could legitimately be said, done and felt from these positions.

\section{Analysis}

The two magazines deploy distinctively different constructions of breasts. Although they both profess to adhere to a Body Positive message, they enact that stance in very different ways. 
The two magazines diverge in their deployment of either feminist or postfeminist discourses that open up different opportunities for talking about breasts and the associated subject positions.

We argue that Seventeen presents contradictory, postfeminist discourse to girls, simultaneously trying to tell girls that all breasts are normal, and that they should feel happy and confident about them, whilst also telling them that their breasts are problematic and need managing. Emerging from this discursive framework, the subject positions made available to girls are the 'dispassionate critic' and the 'consumer', where bras are proposed as the solution to problematic breasts.

On the other hand, Teen Vogue articles reproduce feminist discourse which urges readers to adopt radical, political responses in order to challenge the potentially damaging messages surrounding breast ideals and the sexualisation of breasts. This opens up a 'feminist advocate' subject position for girls that unites writers and readers in collective action. Girls reading Teen Vogue are encouraged to celebrate breast variability yet, like Seventeen readers, are also told to do work on the self. However, by framing this call within a broader feminist collective discourse, we argue it is less contradictory.

\section{Postfeminist discourse - Contradictory body positivity representations}

As noted previously, postfeminist discourse is characterised by multiple and contradictory themes, where feminist messages are at once taken into account and simultaneously undermined. This was evidenced in the Seventeen articles where talk about breasts was underpinned both by Body Positivity discourse and by patriarchal discourse, which were deployed seemingly arbitrarily from one article to the next. 
A considerable number of articles discussing breasts were informed by Body Positivity discourse. Sastre (2014) describes the Body Positive movement as "a loose set of philosophies" (p. 939) dedicated to a rejection of unrealistic ideals and embracing body acceptance. It has roots in the fat acceptance movement that began during second wave feminism and gained further prominence during third wave feminism (Cwynar-Hotra, 2016). But the Body Positivity discourse is not always internally consistent and has a variety of messages with different potential consequences in terms of the ways it enables and constrains young women. For example, on the one hand, Seventeen critiques unrealistic media portrayals of ideal breasts and calls to a normalisation of variety:

"If your only understanding of boobs came from the Victoria's Secret Fashion Show, you'd be confused. Because boobs aren't always symmetrical, perky, round, tan, and encased in a million-dollar diamond-encrusted bra. Real boobs — boobs without bras — come in a million different variations. Some boobs are full, some are flat, some are pointy, some are saggy, some are big, some are small, some are different cup sizes" (Seventeen, 15 Photos Will Make You Love Your Breasts Just as They Are Oct 6, 2017).

But at the same time as advocating for Body Positivity, in the sense of rejecting ideals, there is an accompanying evocation of the necessity to "Love Your Body" (Gill \& Elias, 2014):

"As you know, breasts come in all shapes and sizes and no two - not even the two on your chest — are exactly alike... the way your breasts change might not be the same way your best friend's breasts change. Enjoy your lifetime of being a person 
with boobs. It's a wild ride but also it's incredibly good and fun." (Seventeen, Here's When Your Boobs Really Stop Growing, Sep 18, 2017)

Although a seemingly positive, feminist inflected message, this "Love Your Body" discourse is actually a call to do emotional work. Girls are expected to find their breasts enjoyable, "fun" and "a wild ride". This can be viewed as a pernicious message that expands the site of surveillance from the purely physical to include the emotional (Gill \& Elias, 2014). There is a focus on the regulation of emotions to either embrace the positive or at least hold in check negative affect:

"Whether you were one of the first in your class to get boobs, or you're still waiting for yours to grow, it can be hard not to worry sometimes about how your chest measures up. You may not know how they're supposed to look, if your nipples should be dark or hairy, or if it's normal if your boobs feel a little lumpy. When it comes to your breasts here's what's normal — and what's not...Don't stress too much about your size either way. Everyone's breasts are different, and having small boobs is awesome... Embrace what you have and don't waste time worrying about how your breasts measure up. (Seventeen, 9 Weird Things About Your Boobs That Are Totally Normal, Oct 10, 2017).

Here there is a call to increase the scope of what is considered normal, but by doing so this inadvertently reinforces the concept of 'abnormality'. Thus, the writer takes up the subject position of 'expert', and becomes the final arbiter of constructions of normality and abnormality. This is a textbook example of Sastre's (2014) argument that, "The seemingly well-intentioned [projects on Body Positivity]... reflect, more than reject, the very narratives 
of conformity and regulation they seek to push past.... [They] construct propriety boundaries around normativity despite their paradoxical emphasis on dismantling bodily standards altogether" (p.930). Interestingly, all of these extracts demonstrate Seventeen's broad approach to the challenge of promoting Body Positivity which is to treat, "both the problem and its solutions as personal, individualised and psychologically based" (Gill \& Orgad, 2015, p.331), as opposed to seeing structural or political solutions.

By itself, the deployment of the Body Positivity discourse in Seventeen offers some constructive opportunities for readers to take up. However, across the data set as a whole, there was a far from consistent message and frequent reproduction of the very patriarchal discourses the Body Positivity movement proclaims it seeks to challenge. We argue that young girls reading Seventeen are confronted with the notion that there is an ideal breast size and shape to aspire to, and that not achieving this ideal will be problematic. The ideal breast is sketched out again and again, at times explicitly, at times obliquely. For example, there are articles entitled 14 Hardcore Struggles All Girls With Big Boobs Can Relate To (Oct 3, 2017) and 15 Struggles All Flat-Chested Girls Understand (Jan 12, 2015), but none directed to girls with medium sized breasts, the implication being that they are unproblematic. Here then, the ideal breast emerges as the unspoken space between the metaphorical shadows thrown by inferior breasts.

Frequently the discourses of Body Positivity and unrealistic ideals were entangled, sometimes in the same article, ultimately constructing breasts in a fundamentally contradictory manner. For example, the title of the article below frames the content within Body Positivity discourse, with a call for normalisation of various types of breasts (There Are Seven 
Different Types of Boobs in the World, Apparently... And they're all normal); yet this is undone in the text of the article, where an ideal breast is explicitly described:

"If your breasts appear to be equally full at both the top and bottom, then you've got round boobs. People with these assets don't tend to need particularly structured, padded bras, as you don't need the bra to help shape the breasts — nature's done that for you." (Seventeen, There Are Seven Different Types of Boobs in the World, Apparently... And they're all normal, February 2016).

Those fortunate people who own this physical capital are told that they do not need a bra to correct any imperfection (an issue repeatedly noted in the data which we will discuss later). And the idea that there is such a thing as an ideal is reinforced with an appeal to biological determinism ("nature's done that for you").

One example of how the contradictory discourses shift across time can be seen in Seventeen's coverage of one incident in two separate articles. In April 2016, Victoria's Secret released a new line of unpadded bras. One of the spokespeople for the campaign boldly declared that being confident is now fashionable, implying that small breasts were now officially admitted into the pantheon of acceptable sizes:

“...the brand recently revealed the new addition of bralettes, which feature zero padding, to its ample selection of lingerie. The tag line for the range of bralettes is "No padding is sexy now!" Taylor added, "I think being yourself and being natural nowadays is so in style." (Seventeen, These Victoria's Secret Angels Say You Should Embrace Your Small Breasts, April 2016). 
This advertising campaign was uncritically reported by Seventeen, indirectly reinforcing the message small breasts were once unacceptable. However, one month later, Seventeen reported on a social media backlash against the campaign:

"People say their new ad proves they've been against small boobs all along. With extra emphasis on the word "now", many feel that the brand is implying that no padding was somehow unsexy before. Still others object to the bras themselves, which they say exclude women with larger chests. It's a complaint often directed at Victoria's Secret, which, despite being the number one bra retailer in the world and controlling close to 35 percent of the market, has always put their focus squarely on thin, small-breasted women, even as they promote the look of large breasts with their extreme padding”. (Seventeen, Here's Why Some Women are Angry AF at Victoria's Secret, May 2016).

The backlash focussed on the contradictions and negative messages of the campaign which reinforced unrealistic body ideals. Whilst this report is consistent with Seventeen's professed Body Positivity stance, they failed to make reference to their own original, uncritical coverage of the campaign, and the language used is deliberately neutral ("Why some women are angry..."; "many feel..."; “others object"). In this way, Seventeen typifies the 'double entanglement' of postfeminist discourse (McRobbie, 2009); opportunistically professing Body Positivity credentials, while simultaneously dissociating itself from being seen to take an explicitly confrontational feminist position. In turn, this requires young female readers to negotiate a dilemma, wherein only a month earlier they were exposed to a credulous report 
which reinforced the message that there is such a thing as acceptable breast size which is determined in the public sphere by companies such as Victoria's Secret.

This discourse therefore casts the writer in the subject position of a 'dispassionate critic'. It enables them to offer a tentative rejection of unrealistic body ideals but from a detached, passive stance (literally using passive forms of grammar), rather than as a proactive agent of change. Mirroring the position of the writer, the reader is also offered the same role: as a passive character with no opportunity for anger or protest. There is also no suggestion of allyship between the writer and the reader. It is a lonely, constricted space.

Alongside the 'dispassionate critic', the readers were also regularly offered the opportunity to take up a second subject position, that of 'consumer'. This subject position is offered as a solution in discussions about a range of 'problems' with breasts including breast size, breast shape, the visibility of breasts and non-physical problems such as lack of body confidence. The solution is for the reader to take up the role of consumer by buying and wearing bras. In line with neoliberal rationalities, the reader is told to consume to solve the problems. The following examples are from numerous articles published in Seventeen on how the purchase of bras can 'fix' unsatisfactorily shaped breasts, problematic small breasts, and difficult large breasts (to the point that people with large breasts are told they "can't ever go braless").

"High school junior Andria Castillo...[said]...that she dropped out of taekwondo classes after she began feeling self-conscious about her chest size, which she felt was too small for her age...A properly-fitting sports bra could make a world of difference for you: shop the best sports bras for your cup size here." (Seventeen, More Girls Are Opting Out Of Sports Because Of Their Boobs, May 2016). 
"You can't wear cute strappy summer dresses because you can't ever go braless."

(Seventeen, 15 Problems Only Women With Big Breasts Have in the Summer, June 2015).

The function of bras is not only to correct the physicality of breasts but also to play an important role in perception management.

"And when you complain, your friends hit you with, "But you don't even need a bra." (Because it's not like you have nipples or anything. *sigh*)". (Seventeen, 15 Struggles All Flat=Chested Girls Understand, January 2015).

“A-Cup: Just because you don't need a ton of support, doesn't mean you can skip wearing a sports bra. You want to look for a thicker fabric that will smooth you out". (Seventeen, The Absolute BEST Sports Bras For Every Cup Size, July 2015).

The excerpts above illustrate a challenge for female readers, who are required to negotiate the negative message that, no matter what amount of breast tissue you have, nipples must be hidden, with "smooth you out" being a coded allusion to the rule that the outline of nipples should not be seen. Again, bras are imposed as the unavoidable solution.

Analysing the subject position of 'consumer' in its entirety, we see that it offers readers an individualised approach. The problems, be it having the wrong shaped or sized breasts, having visible nipples, or not being confident enough, are located within the person, with the solution similarly located. In response to their flawed physical and emotional states, the 
individual is called upon to purchase a resolution. The consumption of bras is presented as the easy road to self-transformation. In doing so, this subject position constrains what the reader can legitimately do and feel in relation to their breasts. This responds to the symptom, not the cause of the problem, i.e. the wider cultural conditions that reproduce unrealistic ideals of breasts.

Feminist discourse - Socio-cultural analysis

Unlike the individualistic, neoliberal, consumptive rationalities of postfeminist discourse in Seventeen, in Teen Vogue, a feminist-informed discourse offers structural and socio-cultural analysis of breasts.

Teen Vogue highlights the dominant media discourse that constructs breasts as sexual. Their response to that message is consistently confrontational, rejecting the unspoken assumption that breasts are inherently and unavoidably sexual.

"Men have long enjoyed freeing their nipples, but women are stigmatized for the same privilege...A woman's nipple, even if she is breastfeeding, the ultimate act of innocence, is sexualized". (Teen Vogue, Why Women's Nipples Are Inciting Outrage In Times Square And On Instagram, August 2015).

A social constructionist critique is offered: breasts are not inherently sexual, rather they are sexualised by society. Teen Vogue introduces a number of explicitly political ideas in relation to the sexualisation of breasts. Here we can see reference to the sexual double standard as applied to the acceptability of male vs female nipples. This feminist argument becomes even 
more explicit with the frequent evocation of the feminist movement in relation to breasts and the wearing of bras.

“...women have long been harshly and unfairly policed for the way we dress, so going braless not only serves as a daring style statement, but a trend that boasts a bold feminist message". (Teen Vogue, 10 Times Celebs Convinces Us To Try The BraLess Trend, November 2017).

Teen Vogue also urges readers to tackle the origin of the messages, arguing that the responsibility for change lies with people in positions of authority, not with individuals who might unwittingly reproduce dominant discourses. In the example below, which reported on an incident in an American High School where boys stuck up posters saying that bra straps were distracting them, Teen Vogue advocates an innovative response, where the boys are positioned as patsies of the patriarchal system:

“They aren't to blame for this sexist response, but we know who is. So instead of being angry at the boys who wrote that poster, let's focus on challenging the people who teach them those ideas and on dismantling the system that allows them to do so. We should be questioning authoritative figures who tell young boys that girls are just a distraction, that their bodies are bad, and that they need to change their appearance to cater to boys' sexuality”. (Teen Vogue, Boys Calling Bra Straps Distracting Is Part Of A Larger Problem, June 2017).

Through the repeated use of the (first person, plural) pronoun 'we', the writer actively positions themselves alongside the reader, facing the same injustices and potentially working 
collectively as a community. This is an example of how the feminist discourse in Teen Vogue opens up the subject position of 'feminist advocate' for their readers. Writers and readers are invited to work together in resisting patriarchal standards of femininity, promoting gender equality, and to engage in active, political critique of how those concepts are applied to the self and the body. It also relocates potentially troubling experiences associated with breasts away from being a lone, personal problem, to a wider, socio-cultural and political issue that can be challenged.

This subject position enables writers to deploy politically informed terminology such as 'patriarchy', 'toxic masculinity', 'double standards', and 'the male gaze' throughout the magazine. Conversely, the word 'feminist' or 'feminism' or any of these associated terms never appeared in any of the Seventeen articles selected for analysis.

Whilst Seventeen switches between two discourses, embracing Body Positivity on the one hand, and upholding unrealistic ideals of beauty on the other, Teen Vogue tries to challenge the notion of breast ideals by encouraging girls to embrace variability. Teen Vogue articles acknowledge girls' breasts come in a spectrum of shapes and sizes, and highlights that individual changes in breasts will also occur across the menstrual cycle, and across a lifespan.

"Your boobs can change a full size during a single menstrual cycle, so don't be surprised that they go through a lot in your life. From childhood on, breasts will change size and shape periodically, so cherish what you have going on now before it morphs into something even better.” (Teen Vogue, Fun Facts About Your Boobs You Probably Didn't Know, April 2016). 
We argue that this is potentially empowering, offering girls information and advice to improve their knowledge, navigate their relationships with their bodies across the lifespan, and reject the socially constructed idea that there should only be one beauty standard. Teen Vogue explicitly acknowledges that breast ideals are promoted in the media but they challenge the value of that message and, by consistently highlighting how even the media created ideal breast is subject to change, undermine the very logic of there being an ideal. Thus, unlike Seventeen, the problem of striving to attain an ideal breast is rejected as a legitimate goal by Teen Vogue.

\footnotetext{
"Women's bodies are constantly being critiqued. Whether it's unwelcome comments from others, or sometimes even criticism of ourselves, it seems like someone always has something to say. Worse, women are also constantly made to feel like they should look a certain way... The bottom line is that all bodies are beautiful, "trends" or not. Instead of comparing our bodies or idealizing one certain feature, we should focus on keeping ourselves healthy and strong. What should be trending is body confidence, no matter your size or shape" (Teen Vogue, Social Media Reacts To Article Claiming "Boobs Are Back", August 2017).
}

Once again we see the call to a sense of the collective ("ourselves", "we") and a calling forth of the 'feminist advocate' to resist body ideals. However, in both this extract and the previous one we see evidence of the 'Love Your Body' discourse and a call for psychological work on the self ("all bodies are beautiful", "cherish what you have"). Riley, Evans, Elliott, Rice and Marcek (2017) say that this discourse "deepen[s] expectations of self-improvement and selftransformation, while also constructing women as inherently flawed” (p. 7). However, this 
neoliberal call for readers to work on themselves is at least softened by framing it as a collective endeavour (“Keep ourselves healthy and strong”).

\section{Discussion}

The content of Seventeen and Teen Vogue magazines reaches millions of adolescent girls (Fernandez, 2017; Hearst, 2019), dispensing information, advice and idealised constructions of femininity and the female body. Despite breasts being a key signifier of femininity and an area of concern related to body image, there is a dearth of literature that critically examines the media constructions, discourses and subject positions made available to girls and young women.

Girls' magazines have long been criticised for their role in conveying unrealistic, patriarchal standards of beauty to young, impressionable women (e.g. Faludi, 1991). Our analysis shows the medium is not homogenous and not necessarily damaging. We argue there are two distinctly different discourses deployed across the magazines we examined. In Seventeen we see a pervasive postfeminist inflected discourse that revolves around the contradictions inherent in the dual promotion of Body Positivity and unrealistic body ideals. Whereas, in Teen Vogue we see a more coherent feminist discourse that allies Body Positivity with a socio-cultural and political critique of media representations of breasts.

Both magazines take a Body Positivity stance by attempting to dismantle body ideals through the expansion of the boundaries of what is 'normal'. However, this inadvertently reflects and magnifies, rather than rejects, normative standards (Cwynar-Horta, 2016; Sastre, 2014). Seventeen and Teen Vogue both attempt to promote empowerment through increased 
confidence and a call to 'Love Your Body', but in the process weigh girls down with more targets. Not only are girls called upon to have a beautiful body, it has to be accompanied by a beautiful mind that needs to be affirming and self-assured (Gill \& Elias, 2014). Sastre (2014) has critiqued the Body Positivity movement for its misleading simplicity, and called for a more radical alternative that replaces "Body Postivity's narrative of success with uncertainty" (p.939). And more recently, the unattainable call to 'Love Your Body' has been challenged in the public realm. Commentators have advocated stepping away from surveillance of the body entirely, into a Body Neutrality space that offers a different, more relaxed position for girls to inhabit, where incessant attention on the body is unnecessary (Kessel, 2018; Moss, 2019). Whilst Body Positivity appears in ostensibly similar ways in each magazine, its effects are moderated by the postfeminist or feminist discourses with which it is allied. We interpret Seventeen's overarching discourse as typifying neo-liberal, postfeminism, where "personal change through consumerism is coded as empowerment" (Anderson, 2014, p.8). The predominant subject position that is made available to readers is that of the consumer. This is presented as a positive solution to dissatisfaction and discontent. Consumption, in the form of buying bras, is constructed as a lone, individual act which can armour the reader against societal pressures and judgements. However, this solution is fundamentally isolating, where the unsupported individual is expected to manage the problem on their own, and wider, structural problems are left unchallenged. That is not to say that Seventeen does not acknowledge these wider issues, with readers invited to take up the subject position of 'dispassionate critic'. This position enables them to observe the problems but not to actively confront them. This individualised response to gender inequality means that underlying social, structural, and ideological problems remain unchallenged. 
Seventeen has been criticised in the past for failing to give girls models for liberation (Peirce, 1990; Davalos et al., 2007). Offering the position of the 'dispassionate critic' could be located as part of a wider trend where individuals working in organisations may tone down feminist ideology in an attempt to make it more palatable (Giffort, 2011). Indeed, when Keller interviewed four New York based current or former editors of teen titles in 2011, they all agreed that even printing the "f-word - feminism" was a problem for mainstream publications. This is as a result of them operating within a commercial environment that "fits better with an individualistic and commercialised form of postfeminism...neglecting a larger analysis of structural barriers and power relations" (Keller 2011, p.1).

In stark contrast, in the current study, Teen Vogue's overtly political stance can be seen in articles where they re-define the role and meaning of breasts and expose the underlying gender inequalities and double standards. In doing so, they attempt to actively re-constitute gender and sexual relations, not simply negotiate and manage existing inequalities. The overt use of feminist terminology in Teen Vogue articles also demonstrates the magazine's commitment to drive forward the feminist agenda, despite the constraints of being positioned in a commercially driven and postfeminist magazine market. This is important because, as Pomerantz, Raby and Stefanik (2015) note, girls often lack the language of feminism to articulate their experiences and feelings related to gender injustice and oppression. This exposure to feminist terminology can "facilitate girls' ability to articulate and combat their everyday experiences of sexism as a collective, social problem, rather than as individual and isolated moments" (p.204).

Teen Vogue seems to have flouted the commercially driven industry rules centred around consumption, and appear to be moving in a more progressive direction. Teen Vogue has 
increasingly been championed in the blogosphere for actively repositioning itself away from the industry-standard focus on fashion and celebrity gossip towards a passionate, informed, and progressive "woke" digital brand (Keller, 2017). Yet in academic literature it has only been mentioned in passing as being "a hotspot of 'woke' writing for teens - a space for youth waking up to feminist ideas" (Riley et al., 2017, p. 7). A key turning point was the arrival of Elaine Welteroth as editor-in-chief followed by Phillip Picardi, where the magazine increased its coverage of political and social justice issues (Warrington, 2017). For example, the journalist Lauren Duca recently published a series of 'Thigh High Politics' op-ed articles, including critical coverage of President Trump's campaign (Duca, 2016) and the accusations of sexual misconduct against him (Duca, 2017). Teen Vogue also now publish a regular "Woke List" newsletter that includes articles on LGBTQ issues, immigration and sex positivity.

In a challenging media market, with declining print sales and the recent closure of a number of lifestyle and girls' magazines (Carter, 2013; Rowlands, 2013), publishers have needed to creatively reorient themselves within the digital mediascape. For Teen Vogue this has seemingly involved distinguishing themselves from competitors by adopting and commodifying a distinctive political, feminist and 'woke' identity. With research documenting how groups of girls and young women are increasingly harnessing digital media and web 2.0 technologies to engage with politics, political activism and feminist issues (Dejmanee, 2018; Jackson, 2018; Rúdólfsdóttir \& Jóhannsdóttir, 2018), Teen Vogue has capitalised on this emerging market, cultivating a niche audience that identifies as politically progressive, and providing opportunities for companies to market to this demographic (Keller, 2017). Following Keller (2017), we argue this commercial imperative should not distract from how Teen Vogue has provided a platform for feminist writers to disseminate 
their work to youth audiences. Indeed, this is a valuable step forward in the media industry, particularly considering the wider postfeminist culture in which feminist writers are often concerned that their work may be misrepresented (Boynton, 2012).

\section{Implications/future work}

Based on the findings of this study, we recommend that researchers work with two key audiences: 1) magazine editors and journalists, and 2) magazine readers. Editors and journalists have a responsibility to be more socially aware of how they chose to portray and discuss breasts. Strategies that feminist writers and research scholars can use to facilitate this are to offer public recognition for examples of good practice, and to shine a light on the diverse ways in which girls are engaging with a range of contemporary political issues. This type of feedback and dialogue can open up thinking about creative ways in which magazines can engage with feminism and increase the value of their brand, whilst maintaining their commercial interests. This approach has had success in the past, for example, Braun's (2012) collaboration with a Cosmopolitan magazine journalist, illustrating how mainstream media can be useful allies and important vehicles for promoting critical work.

In addition to critically evaluating and informing the content of magazines, it is also important to consider how this material is received. We propose that critical pedagogy is a valuable tool to help cultivate girls' critical media literacy and support them in negotiating the complex postfeminist messages in magazines. Going beyond the standard use of focus groups as a means to collect data for audience reception analysis, we propose actively working with groups of girls to engage them in teaching and learning about bodies and the media, and to "open up spaces to explore meanings of femininity that escape limiting, repressive boundaries" (Jackson, Vares \& Gill, 2013, p.144). Calder-Dawe's (2014) youth 
workshop resources - Gender, Sexism and Social Activism - offer a treasure trove of practical activities to engage young people in creative and critically reflective practice. Harnessing these resources, we recommend that workshops can be used to introduce groups of girls to social constructionist analyses of gender and power and invite them to explore these ideas by engaging with girls' magazines, and reflecting on the messages, images and content they contain.

\section{Conclusion}

Adolescence is a turbulent time, when girls' bodies are changing and their identities are forming. Breast development in particular is the most visible indicator of puberty and physical change. The norms and ideals presented in magazines become the standards by which women judge their bodies. Our research suggests the feminist discourse deployed in Teen Vogue offers constructive opportunities for girls and young women to engage with feminist politics, and provides a position from which to collectively critique and reject patriarchal standards of beauty. On the other hand, the postfeminist discourse deployed in Seventeen requires readers to negotiate a series of challenging dilemmas and potentially confusing messages, where individualistic consumerist solutions are offered as the only recourse. We conclude that a collaborative effort between editors, journalists, feminist writers and research scholars is needed to deliver consistent feminist messages, reject dominant ideologies and empower girls. In addition, teenage girls need support to improve their critical literacy to negotiate these media discourses. 


\section{Declaration of conflicting interests}

The author(s) declared no potential conflicts of interest with respect to the research, authorship, and/or publication of this article.

\section{Funding acknowledgement}

This research received no specific grant from any funding agency in the public, commercial, or not-for-profit sectors.

\section{References}

Anderson, K. J. (2014). Modern misogyny: Antifeminism in a post-feminist era. Oxford, UK: Oxford University Press.

Avsar, D. K., Avgit, A.C., Benlier, E., Top, H., \& Taskinalp, O. (2010). Anthropometric breast measurement: a study of 385 Turkish female students. Aesthetic Surgery Journal, 30, 44-50.

Ballentine, L., \& Ogle, J. (2005). The Making and Unmaking of Body Problems in Seventeen Magazine, 1992-2003. Family and Consumer Science Research Journal, 33(4), 281307.

Beale, K., Malson, H., \& Tischner, I. (2016). Deconstructing "real” women: Young women's readings of advertising images of "plus-size" models in the UK. Feminism \& Psychology, 26(3), 378-386.

Boynton, P. (2012). Getting the press we deserve: Opportunities and challenges for innovative media practice. Feminism \& Psychology, 22(4), 536-540.

Braun, V. (2012). Petting a snake? Reflections on feminist critique, media engagement and 'making a difference'. Feminism \& Psychology, 22(4), 528-535. 
Brookes, F., \& Kelly. P. (2009). Dolly girls: tweenies as artefacts of consumption. Journal of Youth Studies, 12(6), 599-613.

Brooks-Gunn, J., Newman, D. L., Holderness, C., \& Warren. M. P. (1994). The experience of breast development and girls' stories about the purchase of a bra. Journal of Youth Adolescence, 23(5), 539-565.

Brown, N., Smith, J., Brasher, A., Risius, D., Marczyk, A., \& Wakefield-Scurr, J. (2017). Breast health education for schoolgirls: why, what, when and how? Breast Journal. 24(3), 377-382.

Calder-Dawe, O. (2014). Gender, Sexism and Social Activism: A youth workshop resource. Auckland: Sexual Politics Now, School of Psychology, University of Auckland. Retrieved from: https://researchspace.auckland.ac.nz/bitstream/handle/2292/22235/ Sexual\%2BPolitics\%2BNow\%2BYouth\%2BWorkshop\%2BResource.pdf?sequence= $\underline{10}$

Carter, M. (2013, May 14). Teen mags: Still a girl's best friend? The Independent. Retrieved from: https://www.independent.co.uk/life-style/health-andfamilies/features/teenmags- still-a-girls-best-friend-8614418.html

Chow, J. (2004). Adolescents' perceptions of popular teen magazines. Journal of Advanced Nursing, 48(2), 132-139.

Chittenden, T. (2010). Digital dressing up: modelling female teen identity in the discursive spaces of the fashion blogosphere. Journal of Youth Studies, 13(4), 505-520.

Conde Nast Publications. (2017). Teen Vogue Media Kit. In Teen Vogue (Ed.). Retrieved from: http://www.condenast.com/brands/teen-vogue/ 
Croll, J. (2005). Body image and adolescents. In M. Story \& J. Stang (Eds.), Guidelines for adolescent nutrition services (pp.155-166). Minneapolis, MN: Center for Leadership, Education and Training in Maternal and Child Nutrition, Division of Epidemiology and Community Health, School of Public Health, University of Minnesota.

Cwynar-Horta, J. (2016). The commodification of the Body Positive movement on Instagram. Stream: Inspiring Critical Thought, 8(2), 36-56.

Davalos, B., Davalos, R. A., \& Layton, H. S. (2007). III. Content analysis of magazine headlines. Changes over three decades. Feminism \& Psychology, 17(2), 250-258.

Davies E., \& Furnham, A. (1986). Body satisfaction in adolescent girls. British Journal of Medical Psychology, 59(3), 279-287.

Dejmanee, T. (2018). Popular feminism and teen girl fashion blogs. Continuum, 32(3), 345354.

Dohnt, H., \& Tiggemann, M. (2006). The contribution of peer and media influences to the development of body satisfaction and self-esteem in young girls: A prospective study. Developmental Psychology, 42(5), 929-936.

Duca, L. (2016, December 10). Donald Trump is Gaslighting America. Teen Vogue. Retrieved from: https://www.teenvogue.com/story/donald-trump-is-gaslighting$\underline{\text { america }}$

Duca, L. (2017, December 15). We Need to Reckon With Donald Trump's Alleged Sexual Misconduct. Teen Vogue. Retrieved from: https://www.teenvogue.com/story/ weneed-to-reckon-with-donald-trumps-alleged-sexual-misconduct

Faludi, S. (1991). Backlash: The undeclared war against American women. New York: Crown Publishing Group.

Fernandez, C. (2017). Teen vogue digital editorial director Philip Picardi to also oversee Allure digital. The Business of Fashion, 14 November. 
Finders, M. J. (1996). Queens and teen zines: Early adolescent females reading their way toward adulthood. Anthropology \& Education Quarterly, 27(1), 71-89.

Firminger, K. B. (2006). Is he boyfriend material? Representation of males in teenage girls' magazines. Men and Masculinities, 8(3), 298-308.

Frost, L. (2001). Young women and the body: A feminist sociology. Basingstoke, UK: Palgrave.

Gefen, A., \& Dilmoney, B. (2007). Mechanics of the normal woman's breast. Technology \& Health Care, 15, 259-271.

Giffort, D. M. (2011). Show or tell? Feminist dilemmas and implicit feminism at girls' rock camp. Gender \& Society, 25(5), 569-588.

Gill, R. (2007). Postfeminist media culture: Elements of a sensibility. European Journal of Cultural Studies, 10(2), 147-166.

Gill, R. (2016). Post-postfeminism?: New feminist visibilities in postfeminist times. Feminist Media Studies, 16(4), 610-630.

Gill, R., \& Elias, A. S. (2014). ‘Awaken your incredible': Love your body discourses and postfeminist contradictions. International Journal of Media \& Cultural Politics, $10(2), 179-188$.

Gill, R., \& Orgad, S. (2015). The confidence cult (ure). Australian Feminist Studies, 30(86), 324-344.

Grabe, S., Ward, L. M., \& Hyde, J. S. (2008). The role of the media in body image concerns among women: A meta-analysis of experimental and correlational studies. Psychological Bulletin, 134(3), 460-476.

Grogan, S., Gill, S., Brownbridge, K., Kilgariff, S., \& Whalley, A. (2012). Dress fit and body image: A thematic analysis of women's accounts during and after trying on dresses. Body Image, 10, 380-388. 
Hawkins, N., Richards, P. S., MacGranley, H. \& Stein., D. M. (2004). The impact of exposure to the thin ideal media image on women. Eating Disorders, 12(1), 35-50.

Hearst. (2019). Seventeen Media Kit. Retrieved from:http://www.seventeenmediakit.com/r5/ showkiosk.asp?listing_id=5387886\&category_code=digi\&category_id=77067

Jackson, S. (2005). 'I'm 15 and desperate for sex': 'Doing' and 'Undoing' desire in letters to a teenage magazine. Feminism \& Psychology, 15(3), 295-313.

Jackson, S. (2018). Young feminists, feminism and digital media. Feminism \& Psychology, 28(1), 32-49.

Jackson, S., \& Westrupp, E. (2010). Sex, postfeminist popular culture and the pre-teen girl. Sexualities, 13(3), 357-376.

Jackson, S., Vares, T., \& Gill, R. (2013). 'The whole playboy mansion image': Girls' fashioning and fashioned selves within a postfeminist culture. Feminism \& Psychology, 23(2), 143-162.

Jones, D. C., Vigfusdottir, T. H., \& Lee, Y. (2004). Body image and the appearance culture among adolescent girls and boys: An examination of friend conversations, peer criticism, appearance magazines, and the internalization of appearance ideals. Journal of Adolescent Research, 19(3), 323-339.

Kaplan, E. B., \& Cole, L. (2003). 'I want to read stuff on boys': White, Latina, and black girls reading Seventeen magazine and encountering adolescence. Adolescence, $38(149), 141-159$.

Karlyn, K. R. (2009). Scream, popular culture, and feminism's third wave. In H. Addison, M. K. Goodwin-Kelly \& E. Roth (Eds.) Motherhood Misconceived: Representing the Maternal in US Films. Albany, New York: State University of New York Press.

Keller, J. (2011). Feminist editors and the new girl glossies: fashionable feminism or just another sexist rag? Women's Studies International Forum, 34(1), 1-12. 
Keller, J. (2015). Girl power's last chance? Tavi Gevinson, feminism, and popular media culture. Continuum, 29(2), 274-285.

Keller, J. (2017, December 17). Being woke is profitable: Teen Vogue made waves this year. The Conversation. Retrieved from: https://theconversation.com/being-woke- isprofitable- teen-vogue-made-waves-this-year-88923

Kessel, A. (2018, July 23). The rise of the body neutrality movement: 'If you're fat, you don't have to hate yourself'. The Guardian. Retrieved from: https://www.theguardian. com/lifeandstyle/2018/jul/23/the-rise-of-the-body-neutrality-movement-if-youre-fatyou-dont-have-to-hate-yourself

Lynn, M. (2009). Determinants and consequences of female attractiveness and sexiness: Realistic tests with restaurant waitresses. Archives of Sexual Behaviour, 38, 737-745.

Manning, J., Scutt, D., Whitehouse, G., \& Leinster, S. (1997). Breast asymmetry and phenotypic quality in women. Evolution and Human Behavior, 18, 223-236.

McGrath, M. H., \& Mukerji, S. (2002). Plastic surgery and the teenage patient. Journal of Pediatric and Adolescent Gynecology, 13(3), 105-118.

McRobbie, A. (2000). Feminism and Youth Culture (2nd edn.). Macmillan Press: London.

McRobbie, A. (2009). The aftermath of feminism: Gender, culture and social change. Sage: London.

Millsteed, R., \& Frith, H. (2003). Being large-breasted: women negotiating embodiment. Women's Studies International Forum, 26(5), 455-465.

Moss, B. (2019, May 15). Isn't it time we became body neutral? Instead of loving our flaws, we should forget them. The Telegraph. Retrieved from: https://www.telegraph.co.uk/ health-fitness/body/rather-body-positive-would-healthier-just-body-neutral/

Pattee, A. (2004). When in doubt, choose "B". Encoding teenage girls' magazine quizzes. Feminist Media Studies, 9(2), 193-207. 
Peirce, K. L. (1990). A feminist theoretical perspective on the socialization of teenage girls through Seventeen magazine. Sex Roles, 23, 491-500.

Pomerantz, S., Raby, R., \& Stefanik, A. (2013). Girls run the world? Caught between sexism and postfeminism in school. Gender \& Society, 27(2), 185-207.

Pruchniewska, U. M. (2017). Branding the self as an 'authentic feminist': negotiating feminist values in post-feminist digital cultural production. Feminist Media Studies. $18(5), 810-824$.

Reaby, L. L., Hort, L. K., \& Vandervord, J. (1994). Body image, self-concept, and selfesteem in women who had a mastectomy and either wore an external breast prosthesis or had breast reconstruction and women who had not experienced mastectomy. Health Care Women International, 15(5), 361-375.

Riley, S., Evans, A., Elliott, S., Rice, C., \& Marecek, J. (2017). A critical review of postfeminist sensibility. Social and Personality Psychology Compass, 11(12).

Robins, R. W., \& Trzesniewski, K. H. (2005). Self-esteem development across the lifespan. Current Directions in Psychological Science, 14(3), 158-162.

Rowlands, B. (2013, Mar 7). The fall and rise of magazines from print to digital. The Guardian. Retrieved from: https://www.theguardian.com/media-network/medianetwork-blog/2013/mar/07/fall-rise-magazines-print-digital

Rúdólfsdóttir, A. G., \& Jóhannsdóttir, Á. (2018). Fuck patriarchy! An analysis of digital mainstream media discussion of the\# freethenipple activities in Iceland in March 2015. Feminism \& Psychology, 28(1), 133-151.

Sastre, A. (2014). Towards a radical body positive. Regarding the online 'body positive movement. Feminist Media Studies, 14(6), 929-943.

Seifert, T. (2005). Anthropomorphic characteristics of centerfold models: Trends towards slender figures over time. International Journal of Eating Disorders, 37(3), 271-274. 
SimilarWeb. (2019). Retrieved from:https://www.similarweb.com/website/seventeen.com? competitors=teenvogue.com

Slater, A., \& Tiggemann, M. (2010). Body image and disordered eating in adolescent girls and boys: A test of objectification theory. Sex Roles, 63(1-2), 42-49.

Slater, A., Tiggemann, M., Hawkins, K., \& Werchon, D. (2011). Just one click: A content analysis of advertisements on teen web sites. Journal of Adolescent Health, 50(4), $339-345$.

Smith, M. D. (2014). Cultural encyclopedia of the breast. Rowman \& Littlefield: Lanham, Maryland.

Swami, V. \& Tovee, M. J. (2013). Men's oppressive beliefs predict their breast size preferences in women. Archives of Sexual Behaviour, 42(7), 1199-1207.

Tantleff-Dunn, S., \& Thompson, K. (2000). Breast and chest size satisfaction: Relation to overall body image and self-esteem. Eating Disorders Journal of Treatment and Prevention, 8(3), 241-246.

Ward, L. M., Merriwether, A. \& Caruthers, A. (2006). Breasts are for men: Media, masculinity ideologies, and men's beliefs about women's bodies. Sex Roles, 55(9-10), 703-714.

Warrington, R. (2017, February 25). Inside Teen Vogue: 'Our readers consider themselves activists'. The Guardian. Retrieved from: https://www.theguardian.com/media/2017/ feb/ 25/teen-vogue-readers-consider-themselves-activists

Willig, C. (2013). Introducing qualitative research in psychology $\left(3^{\text {rd }}\right.$ ed). Berkshire: Open University Press. 


\section{Biographical Note}

Nicola Brown is a Reader in Female Health at St Mary's University and teaches across a range of undergraduate and postgraduate programmes in the Department of Health Science. Her research interests lie in the area of female health and exercise, including breast pain and bra fit issues in exercising females and breast education of adolescent schoolgirls. Nicola is a member of the Research Group in Breast Health at the University of Portsmouth and is on the executive committee of the Women in Sport and Exercise Academic Network.

Christine Campbell is a Senior Lecturer in Psychology at St Mary's University, Twickenham, UK. She is the treasurer of the British Psychological Society Psychology of Sexualities Section committee and organises their annual conference. Her research interests lie in the area of romantic relationships, specifically consensual non-monogamies and she is on the organising committee for the biannual Non-Monogamies and Contemporary Intimacies conference.

Craig Owen is a senior lecturer in psychology. His research draws on critical psychology and sociology. His $\mathrm{PhD}$ research focused on the performance of masculinities in capoeira and Latin and ballroom dance classes. Currently, he is collaborating on a number of research projects that explore the negotiation of gender identities in different social contexts. Recent publications and co-authored works include How do men's magazines talk about penises? (Journal of Health Psychology), 'Pra Homem, Menino e Mulher'?: Problematizing the Gender Inclusivity Discourse in Capoeira (International Review for the Sociology of Sport) and A poststructuralist-informed inclusive masculinity theory (Journal of Gender Studies). 
Atefeh Omrani is a final year PhD student at St Mary's University, Twickenham and a member of the Research Group in Breast Health at the University of Portsmouth. Her research interests are in the areas of breast health, breast education, female health and wellbeing and survey development, particularly for adolescents. She has more than five years research experience in a multidisciplinary area including midwifery, breast education, and survey development and utilises both quantitative and qualitative research methods. She also contributes to teaching in BSc Nutrition and Health and Exercise Science degree programmes at St Mary's University. 